\title{
Surgical management of multiple ventricular septal defects: The role of the felt sandwich technique
}

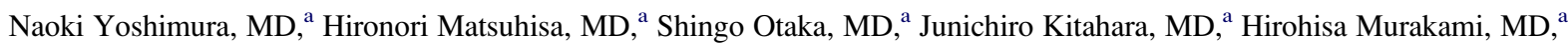 \\ Keiichiro Uese, MD, ${ }^{\mathrm{b}}$ Fukiko Ichida, MD, ${ }^{\mathrm{b}}$ and Takuro Misaki, $\mathrm{MD}^{\mathrm{a}}$
}

\begin{abstract}
Objective: Recently, the felt sandwich technique has been widely used to close muscular ventricular septal defects. We evaluated the early and midterm results of our strategy (a combination of the sandwich technique and direct closures) and assessed the role of the sandwich technique in the treatment of multiple ventricular septal defects.
\end{abstract}

\begin{abstract}
Methods: Twenty-nine consecutive patients underwent an operation for multiple ventricular septal defects and associated cardiac malformations. They included 17 boys and 12 girls with a median age of 6.0 months. Thirteen patients had 4 or more ventricular septal defects (Swiss cheese septum).

Results: There was no surgical or follow-up mortality, and no reoperations were required. There were no cases of heart block and no significant residual shunts in the latest follow-up study. Two patients with Swiss cheese septum had postoperative congestive heart failure. Three muscular ventricular septal defects were closed with the sandwich technique in these 2 patients, whereas 1 or fewer ventricular septal defects were closed with the sandwich technique in the other 27 patients. Seven $(77.8 \%$ ) of 9 patients who underwent the sandwich procedure had septal dysfunction, whereas $5(25.0 \%)$ of the other 20 patients showed septal dysfunction $(P<.05)$.

Conclusions: The outcome of the surgical repair of multiple ventricular septal defects was satisfactory. Although the sandwich technique is simple and effective, the use of numerous felt patches disturbed the movement of the interventricular septum. An effort should be made to close the muscular ventricular septal defect directly to avoid postoperative cardiac dysfunction. Large apical ventricular septal defects, especially those located just underneath the moderator band, are considered suitable for the sandwich technique.
\end{abstract}

The surgical management of multiple ventricular septal defects (VSDs) remains controversial and a challenge. It is frequently associated with operative mortality and complications, including residual VSDs, ventricular dysfunction, and complete heart block. ${ }^{1-4}$ Several techniques that avoid performance of a left ventriculotomy have been described to prevent these complications. ${ }^{4-6}$ Recently, a novel technique was introduced for the closure of muscular VSDs by sandwiching the septum between 2 felt patches placed in the left and right ventricles (the felt sandwich technique). This simple technique does not require any special devices, a prolonged surgical time, or a left ventriculotomy. ${ }^{7-10}$

We have developed a treatment strategy that uses the felt sandwich technique and direct closure of VSDs. The aim of this strategy was to close all VSDs without either a left ventriculotomy or sectioning of the major trabeculae, including the moderator band. The present study evaluated the early and midterm results of this strategy and assessed the role

From the First Department of Surgery ${ }^{\mathrm{a}}$ and the Department of Pediatrics, ${ }^{\mathrm{b}}$ University of Toyama, Graduate School of Medicine, Toyama, Japan.

Received for publication May 2, 2008; revisions received July 20, 2008; accepted for publication Aug 31, 2008.

Address for reprints: Naoki Yoshimura, MD, First Department of Surgery, University of Toyama, Graduate School of Medicine, 2630 Sugitani, 930-0194, Toyama, Japan (E-mail: ynaoki@med.u-toyama.ac.jp).

J Thorac Cardiovasc Surg 2009;137:924-8

$0022-5223 / \$ 36.00$

Copyright (c) 2009 by The American Association for Thoracic Surgery doi:10.1016/j.jtcvs.2008.08.055 of the felt sandwich technique in the treatment of multiple VSDs.

\section{MATERIALS AND METHODS Patients}

Twenty-nine consecutive patients underwent surgical intervention for multiple VSDs and associated cardiac malformations during a 38-month period from February 2005 to March 2008 in our institution. Parents of the patients provided written informed consent before the operations. There were 17 boys and 12 girls with a median age of 6.0 months (range, 8 days -8 years). The patients ranged in body surface area (BSA) from 0.20 to $0.76 \mathrm{~m}^{2}$ (median, $0.30 \mathrm{~m}^{2}$ ) and weighed 3.0 to $18.0 \mathrm{~kg}$ (median, $5.7 \mathrm{~kg}$ ). The associated cardiac malformations included double-outlet right ventricle in 7 patients, tetralogy of Fallot in 4 patients, transposition of the great arteries in 2 patients, coarctation of the aorta in 1 patient, and atrioventricular septal defect in 1 patient. Fourteen patients had isolated multiple VSDs. Nine of 29 patients had undergone previous cardiac operations (Table 1). The interventricular septum was analyzed by means of preoperative cineangiographic analysis in 17 patients. Preoperative cineangiographic analysis demonstrated the presence of multiple VSDs in 11 patients. Five other patients were given a diagnosis of multiple VSDs based on preoperative echocardiographic analysis. Thereafter, the presence of multiple VSDs was preoperatively diagnosed in $16(55.2 \%)$ patients and intraoperatively diagnosed in 13 patients. Twelve patients had 2 VSDs, 4 had 3 VSDs, and 13 had 4 or more VSDs (Swiss cheese septum).

\section{Surgical Technique for Closure of Muscular VSDs}

The details of the surgical technique have been described in previous reports. ${ }^{7,10}$ After achievement of mild-to-moderate hypothermic cardiopulmonary bypass, the aorta was crossclamped, and myocardial protection was achieved with cold blood cardioplegia. ${ }^{11,12}$ A longitudinal right atriotomy was performed, and the interventricular septum was exposed through 


\section{Abbreviations and Acronyms \\ $\mathrm{BSA}=$ body surface area \\ VSD $=$ ventricular septal defect}

the tricuspid valve. A ventriculotomy was not used to access VSDs unless it was required for other repairs, such as a right ventricular outflow tract reconstruction. A combination of different techniques was used to close multiple VSDs. The perimembranous VSD was closed with a Dacron polyester fabric patch. If the patient did not undergo preoperative cineangiographic analysis, meticulous analysis was required to avoid missing muscular VSDs. Muscular VSDs were sometimes found in the malaligned interventricular septum. In these cases blood oozed into the right ventricle, despite adequate left ventricular venting. Identification of muscular VSDs was done by means of gentle probing of the trabeculations with a fine hemostatic forceps to delineate the connection with the left ventricle. The location, number, and size of muscular VSDs were estimated by the meticulous analysis from the right ventricle. Initially, an attempt was made to close the muscular VSDs with mattress sutures reinforced with pledgets or endocardial running sutures by using 6-0 polypropylene sutures (re-endocardialization techniques). When the VSD was located just underneath the moderator band or apex of the heart, where it was difficult to place the exact sutures, it was considered unsuitable for direct closure. The VSD was then closed with the felt sandwich technique. The tip of the right-angled forceps placed in the VSD could be seen in the left ventricle through a perimembranous VSD or through the longitudinal atrioseptostomy. A 3F Nelaton catheter (Bard, Haverhill, Mass) was grasped and pulled back into the right ventricle. The Nelaton catheter led an oversized (2-4 mm larger than the estimated size of the VSD) circular polyester felt patch mounted on a 4-0 braided polyester suture. The suture ends were then passed through a slightly smaller (1-2 mm larger than the estimated size of the VSD) polyester felt patch on the right ventricular side of the septum. The braided polyester suture was then tied, thereby sandwiching the septum between the 2 polyester felt patches.

\section{Echocardiographic Analysis and Follow-up}

Postoperative echocardiograms were performed before hospital discharge to evaluate the residual shunts and cardiac functions. Because patches occupying the interventricular septum might cause left ventricular dysfunction, the relationship between the motion of the interventricular septum and the calculated total patch area/BSA ratio ${ }^{10}$ was evaluated based on the following equation: Total patch area/BSA = the sum total patch area of patches used for closure of all VSDs (in square centimeters)/BSA (in square meters). Follow-up echocardiograms were performed a mean of 7.6 months (range, 1-32 months) after the operation.

\section{Statistical Analysis}

Normally distributed data are expressed as the mean \pm standard deviation, and data not normally distributed are expressed as medians with ranges. The differences between the 2 groups were analyzed by using the Student's unpaired $t$ test for means of continuous variables and the Fisher's exact test for categorical variables.

\section{RESULTS}

\section{Early and Midterm Results}

There were no early deaths. Electrocardiographic analysis showed sinus rhythm in all patients, with a complete right bundle branch block in 13 patients. Two patients with Swiss cheese septum had postoperative congestive heart failure. One patient with double-outlet right ventricle underwent
TABLE 1. Characteristics of the 29 patients

\begin{tabular}{lc}
\hline Age (mo), median (range) & $6(0-104)$ \\
BSA $\left(\mathrm{m}^{2}\right)$, median (range) & $0.30(0.20-0.76)$ \\
Associated cardiac anomalies & \\
Double-outlet right ventricle & 7 \\
Tetralogy of Fallot & 4 \\
Transposition of the great arteries & 2 \\
Coarctation of the aorta & 1 \\
Atrioventricular septal defect & 1 \\
Previous cardiac interventions & \\
Pulmonary artery banding & 5 \\
Blalock-Taussig shunt & 3 \\
Ligation of arterial duct & 2 \\
Unifocalization & 2 \\
Extended aortic arch anastomosis & 1 \\
Arterial switch operation & 1 \\
Tetralogy of Fallot repair & 1 \\
Additional procedures & \\
Double-outlet right ventricle repair & \\
Debanding & 6 \\
Arterial switch operation & 3 \\
Rastelli procedure & 2 \\
Tetralogy of Fallot repair & 2 \\
Atrioventricular septal defect repair & 1 \\
\hline
\end{tabular}

$B S A$, Body surface area.

an arterial switch operation, with intraventricular rerouting at 6 months of age and a weight of $6.2 \mathrm{~kg}$. Postoperatively, marked cardiomegaly and severe pulmonary congestion developed, and the patient could not be weaned from ventilatory support. Fourteen days after the operation, cardiac catheterization revealed a large amount of residual shunt, with a $\mathrm{Qp} / \mathrm{Qs}$ ratio of 6.67. At the time of the second emergency operation, 5 muscular VSDs $(10,6,5,5$, and $3 \mathrm{~mm}$ in diameter, respectively) were identified. Three muscular VSDs were closed by using the sandwich technique, and 2 VSDs were closed directly. Although the pulmonary blood flow decreased, severe left ventricular dysfunction with moderate mitral valve insufficiency developed postoperatively. The patient required prolonged ventilatory support. The left ventricular function was gradually improved by the medical treatment. The postoperative catheterization study, performed at 5 months after the operation, showed a decrease in the volume of the residual shunt $(\mathrm{Qp} / \mathrm{Qs}$ ratio of 1.10) and mitral valve insufficiency. At the 18-month follow-up, the patient was doing well.

Another patient had postoperative congestive heart failure after a Rastelli-type procedure and closure of 3 muscular VSDs $(6,4$, and $4 \mathrm{~mm}$ in diameter, respectively) by using the sandwich technique. Echocardiographic analysis revealed the reduced wall motion of the interventricular septum. Cardiac dysfunction was thought to be caused by a standard VSD patch and the felt patches disturbing the movement of the interventricular septum. The left ventricular function was gradually improved in response to the 


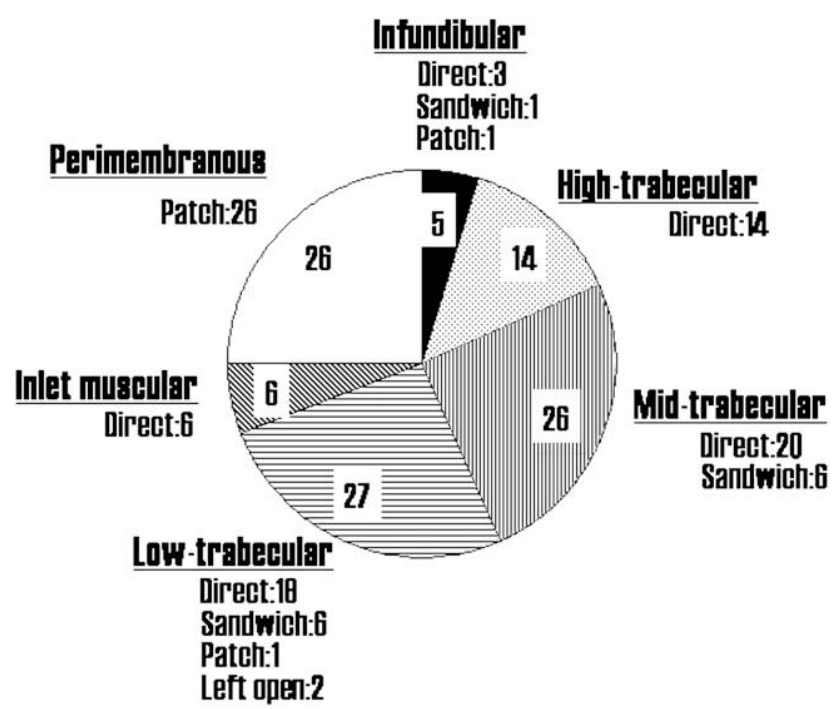

FIGURE 1. Location of the ventricular septal defects and closure techniques.

medical treatment. The follow-up catheterization study, performed at 11 months after the operation, showed an improvement of left ventricular function (ejection fraction of $62 \%$ ). In addition, the residual VSD had also disappeared.

All patients were followed up for a mean of $12.5 \pm 10.4$ months. There were no late deaths. No patient required further surgical intervention. Twenty-three of 29 patients are free of cardiac medications, and the remainder received a combination of diuretics, angiotensin-converting enzyme inhibitors, and/or prostaglandin $\mathrm{I}_{2}$. In 2 patients these medications will be terminated in a few months.

\section{Closures of VSDs}

One hundred two VSDs were closed in 29 patients. The VSDs included 26 perimembranous, 14 high-trabecular, 26 mid-trabecular, 25 low-trabecular, 6 inlet muscular, and 5 infundibular septal lesions, according to the classification of Serraf and associates. ${ }^{1}$ The localization and size of the defects and the techniques of the VSD closure are summarized in Figures 1 and 2. All VSDs located in a high-trabecular portion and the inlet portion could be directly closed. The mean size of the muscular VSDs closed by using the sandwich technique was $5.8 \pm 2.2 \mathrm{~mm}$, and the mean size of the muscular VSDs closed directly was $3.7 \pm 1.0 \mathrm{~mm}$ $(P<.0001)$. Three muscular VSDs were closed with the sandwich technique in 2 patients who had postoperative congestive heart failure, whereas 1 or fewer VSDs were closed with the sandwich technique in the other 27 patients (Table 2).

\section{Echocardiographic Analysis and Follow-up}

The in-hospital echocardiograms demonstrated no residual leakage in 9 patients or only trivial residual leakage in 17 patients. At the latest echocardiographic study, the resid-

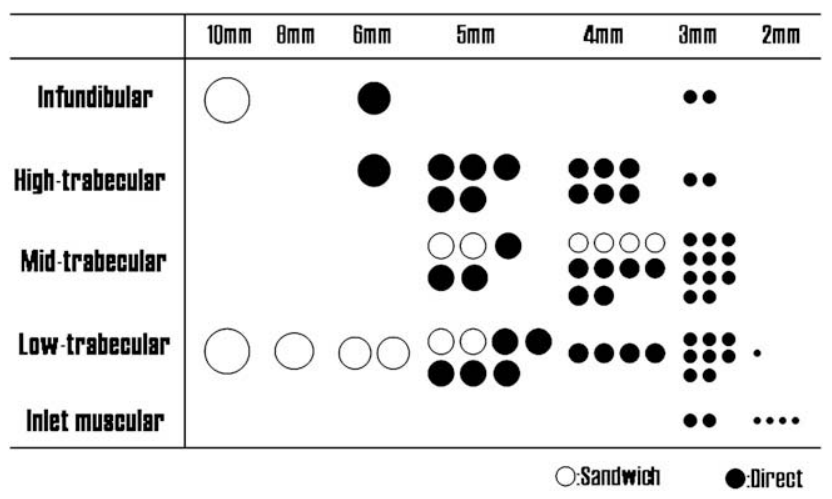

FIGURE 2. Size of the muscular ventricular septal defects and closure techniques.

ual leakage had disappeared in 10 patients and decreased in 2 patients. At the postoperative echocardiographic evaluation, the left ventricular ejection fractions were within the normal ranges in the 27 patients who did not have congestive heart

TABLE 2. Techniques of VSD closure and postoperative septal function

\begin{tabular}{|c|c|c|c|c|c|c|}
\hline \multirow[b]{2}{*}{$\begin{array}{c}\text { Patient } \\
\text { no. }\end{array}$} & \multirow[b]{2}{*}{$\begin{array}{l}\text { No. of } \\
\text { VSDs }\end{array}$} & \multicolumn{3}{|c|}{ Technique of VSD closure } & \multirow[b]{2}{*}{$\begin{array}{c}\text { Total patch } \\
\text { area/BSA }\end{array}$} & \multirow[b]{2}{*}{$\begin{array}{c}\text { Motion } \\
\text { of IVS }\end{array}$} \\
\hline & & Patch & Direct & Sandwich & & \\
\hline 1 & $2(1)$ & 1 & 0 & 1 & 7.09 & Paradoxic \\
\hline 2 & $2(1)$ & 1 & 0 & 1 & 6.58 & Good \\
\hline 3 & $2(1)$ & 1 & 0 & 1 & 3.07 & Good \\
\hline 4 & $2(1)$ & 1 & 1 & 0 & 4.40 & Good \\
\hline 5 & $3(2)$ & 1 & 2 & 0 & 1.87 & Paradoxic \\
\hline 6 & $3(3)$ & 1 & 2 & 0 & 4.01 & Good \\
\hline 7 & $2(1)$ & 1 & 1 & 0 & 4.35 & Good \\
\hline 8 & $2(1)$ & 1 & 1 & 0 & 3.03 & Good \\
\hline 9 & $3(2)$ & 1 & 2 & 0 & 2.45 & Good \\
\hline 10 & $6(5)$ & 1 & 2 & 3 & 20.70 & Paradoxic \\
\hline 11 & $2(1)$ & 1 & 1 & 0 & 4.35 & Good \\
\hline 12 & $6(5)$ & 1 & 4 & 1 & 7.32 & Paradoxic \\
\hline 13 & $5(4)$ & 1 & 1 & 3 & 10.48 & Paradoxic \\
\hline 14 & $5(5)$ & 0 & 5 & 0 & 0 & Paradoxic \\
\hline 15 & $4(3)$ & 1 & 2 & 1 & 9.43 & Paradoxic \\
\hline 16 & $4(3)$ & 1 & 3 & 0 & 2.71 & Good \\
\hline 17 & $6(5)$ & 1 & 4 & 1 & 6.78 & Hypokinetic \\
\hline 18 & $3(2)$ & 1 & 2 & 0 & 2.91 & Good \\
\hline 19 & $4(3)$ & 1 & 2 & 1 & 6.16 & Hypokinetic \\
\hline 20 & $2(1)$ & 1 & 1 & 0 & 1.32 & Good \\
\hline 21 & $4(4)$ & 0 & 3 & 0 & 0 & Good \\
\hline 22 & $5(4)$ & 1 & 4 & 0 & 6.41 & Hypokinetic \\
\hline 23 & $2(1)$ & 1 & 1 & 0 & 1.05 & Good \\
\hline 24 & $2(1)$ & 1 & 1 & 0 & 4.42 & Good \\
\hline 25 & $6(5)$ & 1 & 5 & 0 & 3.80 & Good \\
\hline 26 & $2(1)$ & 1 & 1 & 0 & 3.65 & Paradoxic \\
\hline 27 & $4(3)$ & 1 & 3 & 0 & 2.91 & Good \\
\hline 28 & $8(7)$ & 2 & 6 & 0 & 5.17 & Paradoxic \\
\hline 29 & $2(1)$ & 1 & 1 & 0 & - & Good \\
\hline
\end{tabular}


failure. However, the wall motions of the interventricular septum were paradoxic or hypokinetic in $12(41.4 \%)$ of 29 patients. Seven $(77.8 \%)$ of 9 patients who underwent the sandwich procedure had septal dysfunction, whereas 5 $(25.0 \%)$ of the other 20 patients had septal dysfunction $(P<.05)$. The mean value of the total patch area/BSA ratio ${ }^{10}$ of the patients with septal dysfunction was $7.09 \pm 5.19$, and that of the patients who had normal septal function was $3.21 \pm 1.58(P<.01)$.

\section{DISCUSSION}

Despite advances in the preoperative diagnosis and management, improved surgical techniques, and postoperative care, significant mortality and morbidity is still associated with the treatment of patients with multiple VSDs. Numerous operations and surgical strategies can be found in the medical literature to address the treatment of multiple VSDs. ${ }^{1-10}$ With conventional techniques, ${ }^{1,2,5}$ extensive division of the muscular trabeculations with a right or left ventriculotomy is performed to sufficiently expose the defects. These procedures might substantially compromise ventricular function in small infants. Recently, the felt sandwich technique has been widely used to close muscular VSDs because this technique is simple, safe, effective, and reproducible. ${ }^{7-10}$ The sandwich technique requires neither the transection of muscular trabeculations nor a ventriculotomy. Muscular VSDs, even those that are identified intraoperatively, can be easily closed. Ootaki and colleagues ${ }^{7}$ reported their early experience with 11 patients. They described that the time required for the procedure was less than 20 minutes in each case and that all patients had uneventful postoperative courses. Brizard and coworkers ${ }^{9}$ also described their experience with 14 patients with good results. They concluded that this method might prove especially valuable in complex cases in which there is a need to avoid time-consuming procedures.

We also performed the operation for 29 patients described in the current study with good results. There was no surgical or follow-up mortality in this series, and no reoperation was required. There were no cases of heart block and no significant residual shunts in the latest follow-up study. Although the surgical results were satisfactory, 2 patients with Swiss cheese septum had postoperative congestive heart failure. Cardiac dysfunction was thought to be caused by numerous patches disturbing the movement of the interventricular septum.

Murakami and associates ${ }^{10}$ analyzed the postoperative cardiac function in 36 patients who underwent a closure of multiple VSDs by using the felt sandwich technique. They described that the postoperative left ventricular function in the group with a BSA of less than $0.4 \mathrm{~m}^{2}$ was significantly lower than that in the group with a BSA of $0.4 \mathrm{~m}^{2}$ or greater. They also reported that there was a strong correlation between the postoperative left ventricular ejection fraction and the total patch area/BSA ratio. They concluded that the use of numerous felt patches for small infants caused postoperative cardiac dysfunction.

In the current series 3 muscular VSDs were closed with the sandwich technique in both patients who had postoperative cardiac dysfunction. The calculated total patch area/ BSA ratios of these 2 patients were 20.70 and 10.48 , and their expected postoperative ejection fractions were $33.6 \%$ and $54.2 \%$, respectively. ${ }^{10}$ Postoperative echocardiograms revealed the wall motion of the interventricular septum to be either paradoxic or hypokinetic in $41.4 \%$ of the patients, despite the fact that their global ejection fraction was within the normal range. Most $(77.8 \%)$ of the patients who underwent the sandwich procedure showed septal dysfunction, and the mean value of the total patch area/BSA ratio ${ }^{10}$ of the patients with septal dysfunction was higher than that of the patients with normal septal function. These results were consistent with those of Murakami and associates. ${ }^{10}$

Recently, the trend in congenital heart surgery is toward earlier definitive repair, ${ }^{12}$ and most of the patients in the present study were small infants whose BSAs were less than $0.4 \mathrm{~m}^{2}$. Murakami and associates ${ }^{10}$ proposed pulmonary artery banding for small infants with a BSA less than $0.4 \mathrm{~m}^{2}$, whose cardiac function was strongly influenced by the patch area. However, the preoperative detection of the location and number of muscular VSDs is very difficult, ${ }^{1,2,9}$ especially in patients who did not undergo preoperative cineangiographic analysis. In fact, muscular VSDs were found in 13 of 29 patients intraoperatively. Surgeons should make an effort to reduce the total patch area to preserve the septal function. Our current strategy was implemented to close muscular VSDs directly.

Alsoufi and colleagues ${ }^{13}$ reported a transatrial re-endocardialization strategy that used double-layer superficial running sutures to approximate the trabeculae and eliminate exit defects on the right side of the septum. They described that septal dysfunction as a result of deep suturing in the septum, division of the major trabeculae, or a ventriculotomy was avoided by this technique. Currently, we also use a transatrial re-endocardialization technique as a procedure of choice to preserve septal function. When the VSD was considered unsuitable for direct closure, the felt sandwich technique was used. As a result of this strategy, only 1 or fewer felt patches were used to close muscular VSDs in 27 of 29 patients.

The present study summarized the location and size of VSDs and the closure techniques (Figure 1 and 2) to determine the exact indications of the sandwich technique. Figure 1 shows that $22.6 \%$ of midtrabecular and lowtrabecular VSDs were closed with the sandwich technique, whereas all inlet VSDs and high-trabecular VSDs were closed directly. In practice it is not easy to place the re-endocardialization sutures between the mid-trabecular and lowtrabecular septum and the right ventricular free wall. The moderator band or multiple trabeculations disturb the exact 
sutures. It is also difficult to identify the edge of the defect in these areas. The mean size of the muscular VSDs closed with the sandwich technique was larger than that of the muscular VSDs closed directly. Large apical muscular VSDs, especially those located just underneath the moderator band with a poorly defined muscular rim, were considered suitable for the sandwich technique.

There is a limitation in this study. The movement of the interventricular septum was not evaluated quantitatively. The relationship between the felt patch and regional wall motion was unclear. Further experience and precise evaluations of the septal wall motion are thus needed to clarify the safety margin and adequate indications of the felt sandwich technique for small infants. Tissue Doppler echocardiographic study might be useful to evaluate the regional wall motion of the interventricular septum. ${ }^{14}$

\section{CONCLUSIONS}

The outcome of the surgical repair of multiple VSDs was satisfactory. The sandwich technique is simple and effective for the closure of muscular VSDs. This technique might be useful, especially in complex cases, because it does not require prolonged surgical time. However, the use of numerous felt patches disturbed the movement of the ventricular septum, which caused cardiac dysfunction in infants. To avoid postoperative cardiac dysfunction, the surgeon should try to close the muscular VSD directly, if possible. Large apical muscular VSDs, especially those located just underneath the moderator band with a poorly defined muscular rim, are considered to be suitable for the sandwich technique.

We consider the felt sandwich technique to be a useful tool that can be applied as needed by surgeons in addition to the patching or direct suturing of VSDs.

\section{References}

1. Serraf A, Lacour-Gayet F, Bruniaux J, Ouaknine R, Losay J, Petit J, et al. Surgical management of isolated multiple ventricular septal defects: logical approach in 130 cases. J Thorac Cardiovasc Surg. 1992;103:437-43.

2. Kitagawa T, Durham LA III, Mosca RS, Bove EL. Techniques and results in the management of multiple ventricular septal defects. J Thorac Cardiovasc Surg. 1998; 115:848-56.

3. Black MD, Shukla V, Rao V, Smallhorn JF, Freedom RM. Repair of isolated multiple muscular ventricular septal defects: the septal obliteration technique. Ann Thorac Surg. 2000;70:106-10.

4. Seddio F, Reddy VM, McElhinney DB, Tworetzky W, Silverman NH, Hanley FL. Multiple ventricular septal defects: how and when should they be repaired? J Thorac Cardiovasc Surg. 1999;117:134-40.

5. Myhre U, Duncan BW, Mee RBB, Joshi R, Seshadri SG, Herrera-Verdugo O, et al. Apical right ventriculotomy for closure of apical ventricular septal defects. Ann Thorac Surg. 2004;78:204-8.

6. Bacha EA, Cao QL, Starr JP, Waight D, Ebeid MR, Hijazi ZM. Perventricular device closure of muscular ventricular septal defects on the beating heart: technique and results. J Thorac Cardiovasc Surg. 2003;126:1718-23.

7. Ootaki Y, Yamaguchi M, Yoshimura N, Oka S, Yoshida M, Hasegawa T. Surgical management of trabecular ventricular septal defects: the sandwich technique. J Thorac Cardiovasc Surg. 2003;125:508-12.

8. Kapoor L, Gan MD, Das MB, Mukhopadhyay S, Bandhopadhyay A. Technique to repair multiple muscular ventricular septal defects. J Thorac Cardiovasc Surg. 1999;117:402-3.

9. Brizard CP, Olsson C, Wilkinson JL. New approach to multiple ventricular septal defect closure with intraoperative echocardiography and double patches sandwiching the septum. J Thorac Cardiovasc Surg. 2004;128:684-92.

10. Murakami H, Yoshimura N, Takahashi H, Matsuhisa H, Yoshida M, Oshima Y, et al. Closure of multiple ventricular septal defects by the felt sandwich technique: further analysis of 36 patients. J Thorac Cardiovasc Surg. 2006;132:278-82.

11. Toyoda Y, Yamaguchi M, Yoshimura N, Oka S, Okita Y. Cardioprotective effects and the mechanisms of terminal warm blood cardioplegia in pediatric cardiac surgery. J Thorac Cardiovasc Surg. 2003;125:1242-51.

12. Hasegawa T, Yamaguchi M, Yoshimura N, Okita Y. The dependence of myocardial damage on age and ischemic time in pediatric cardiac surgery. $J$ Thorac Cardiovasc Surg. 2005;129:192-8.

13. Alsoufi B, Karamlou T, Osaki M, Badiwala MV, Ching CC, Dipchand A, et al. Surgical repair of multiple muscular ventricular septal defects: the role of re-endocardialization strategy. J Thorac Cardiovasc Surg. 2006;132:1072-80.

14. Hashimoto I, Hejmadi A, Li X, Jones M, Davis C, Swanson JC, et al. Tissue Doppler-derived myocardial acceleration for evaluation of left ventricular diastolic function. J Am Coll Cardiol. 2004;44:1459-66. 